\title{
EDITORIAL
}

\section{LAS NUEVAS REALIDADES DE LA EDUCACIÓN SUPERIOR EN AMÉRICA LATINA Y EL CARIBE}

Germán Anzola Montero

Rector

En París, del 5 al 9 de octubre de 1998, se realizó la primera Conferencia Mundial sobre Educación Superior, organizada y convocada por la UNESCO. De conformidad con los reportes asistieron 182 países, representantes de sus respectivos gobiernos; se calcula que el número de participantes fue superior a las 4000 personas. Para la Educación Superior colombiana y particularmente para sus Universidades, la conferencia generó grandes expectativas, tanto en los momentos previos, como durante su realización y subsiguientemente. Como actividad preparatoria, la reunión de París estuvo precedida de conferencias a nivel de los diferentes continentes: Asia, Europa, África y América Latina. Específicamente, en noviembre de 1996, en la ciudad de La Habana, Cuba, se llevó a cabo la conferencia para América Latina y el Caribe convocada por el Instituto Internacional para la Educación Superior para América Latina y el Caribe de la UNESCO. Las instituciones más representativas de la región estuvieron presentes y fue allí donde se definió la orientación y los contenidos a presentar en París.

La Conferencia Mundial del 98 tuvo como resultado los documentos: "La Declaración Mundial sobre la Educación Superior en el siglo XXI: Visión y Acción” y "Marco de Acción Prioritaria para el Cambio y el Desarrollo de la Educación Superior". De conformidad con lo expresado en el trabajo del Profesor Rafael Guarda, ex rector de la Universidad de la República (Uruguay), estos textos enfatizaron en el desarrollo futuro de la Educación Superior en el nuevo papel del conocimiento, como instrumento fundamental para el desarrollo sostenible de las sociedades modernas, siendo a partir de este concepto, que se considera a la Educación Superior como un derecho e igualmente como una herramienta vital para la construcción del futuro de toda sociedad. Continúa el Profesor Guarda, que la Educación Superior se contempla como un bien público, lo cual significa que ella es un bien, patrimonio de la sociedad entera, en una nación dada. Ante esta consideración quisiera ratificar que éste es igualmente para la Universidad de Ciencias Aplicadas y Ambientales U.D.C.A, el principio consagrado en su Proyecto Educativo Institucional PEI y en sus Estatutos.

En las declaraciones de la Conferencia, se ratifica la necesaria libertad académica en su seno y el papel de los Estados en el respaldo y fortalecimiento de sus Universidades. Personalmente, añadiría frente a este concepto, dentro de la muy particular organización de la Educación Superior en Colombia, cंcuál ha sido el comportamiento del Gobierno para con las Universidades estatales?, que son de su responsabilidad y, de igual manera, ¿cuáles frente a las Universidades privadas? ¿Qué se ha hecho a partir de las citadas declaraciones?, ¿̇será que después de diez años ese respaldo y fortalecimiento, en lugar de señalarse como un logro, tendremos que identificarlo como una mayor debilidad?

Otro aspecto tratado en las Declaraciones fue el de la democratización de la Educación Superior, expresado en el acceso de hombres y de mujeres con fundamento en sus méritos y lejos de considerar discriminación alguna de raza, de género, de idioma, de religión, de limitaciones físicas o razones económicas, culturales o sociales. También tiene sentido, al hablar de democratización, considerar lo relativo a la gobernabilidad de las Universidades, en lo referente a la activa y decidida participación de los actores en la vida universitaria. ¿́Los diferentes estamentos representados en dichos esquemas de gobierno han sido consecuentes con su compromiso y con su responsabilidad frente a la organización universitaria? Conceptúo, frente al tema de la democratización, en el caso de la U.D.C.A, como el momento de evaluarlo en cada uno de los aspectos, anteriormente señalados, 
cuáles son los resultados concretos al haber consagrado, en nuestros planes de desarrollo similares, consideraciones respecto a la admisión de estudiantes. Hemos construido, como asunto nuevo, la representación en sus máximos órganos de gobierno en la U.D.C.A, la presencia de estudiantes y de profesores.

Continuando con la síntesis de las dos Declaraciones de París, se destacan los siguientes elementos: el significado e importancia que en épocas presentes ha de jugar la educación puramente dirigida a egresados, a adultos y a todos quienes puedan demandar conocimientos ofrecidos por las instituciones de educación superior, hecho este, a lo cual se le dio la denominación de educación para toda la vida. Otro aspecto declarado hace referencia a las relaciones que han de sostener las Universidades con las demás del sistema educativo, haciendo énfasis en la formación de educadores para dichos niveles, procesos de diseño curricular e investigación en aspectos propios de las ciencias de la educación. Se hace especial consideración al tema de las reales y concretas relaciones de las Universidades con la sociedad, hecho denominado y tratado bajo el concepto de pertinencia; se destaca, la función investigativa como quehacer esencial de las universidades, generación de nuevo conocimiento, como atributo incondicional para retroalimentar los procesos docentes y de proyección a la sociedad. Se recomienda, como acción prioritaria, servicio de las Universidades a la comunidad, en especial para atender problemáticas relacionadas con la pobreza, la violencia, la convivencia, la intolerancia y, finalmente, se señala la necesidad de utilizar y de apoyar los procesos de formación superior con las tecnologías de la comunicación e información, instrumentos que han de contribuir con el mejoramiento de la calidad, con el acceso y con la cobertura de la educación superior.

Del 23 al 25 de junio de 2003, se llevó a cabo en París la reunión de seguimiento de la Conferencia Mundial de Educación Superior, denominada París +5 , a la cual no se le dio la connotación de reunión o conferencia de gobiernos, sino que se constituyó en un encuentro de expertos en el tema de la educación superior. En el informe general de la relatoría, se consagra a la educación superior como un bien público y se ratifica la necesaria autonomía de las Universidades, la libertad académica y el deber de los estados para garantizar el sustento y permanente fortalecimiento de las instituciones de edu- cación superior. De manera contraria, se ha pretendido sustituir los conceptos anteriores por otros que conduzcan a interpretar a la educación superior como un "bien público global y como un servicio", en oposición a lo considerado en los autorizados espacios académicos de todo el mundo. Conceptos que no tienen la posibilidad de conciliarse con los de una educación superior, como fuente de la innovación, la creatividad y el pensamiento crítico al servicio de las sociedades.

Resulta de significativa prioridad que las Universidades de América Latina y el Caribe, en el contexto de las anteriores realidades, inicien la preparación para la próxima Conferencia Mundial de Educación Superior, que desde ya viene programando la UNESCO, para el año 2009, en París y que, consecuentemente, por iniciativa de la Directora de UNESCO-IESALC, Doctora Ana Lucia Gazzola y el Director de ANDIFES (Asociación Nacional de Dirigentes de Instituciones Federales de Educación Superior, Brasil), Doctor Paulo Séller (II Encuentro de Redes Universitarias y Consejos de Rectores de América Latina y el Caribe, Caracas, 3 y 4 de mayo de 2007) han impulsado, a nivel de la región y con el apoyo de una excelente nómina de consultores, la preparación del documento titulado "Tendencias de la Educación Superior en América Latina y el Caribe", el cual, con una visión de futuro, propone los términos de referencia para establecer las políticas de Estado en la educación superior, la ciencia y la cultura. La Educación Superior para el Desarrollo Sostenible, se constituye en la idea central del trabajo, que bajo el análisis del contexto regional y mundial, en términos prospectivos, estudiará los retos y las oportunidades de la educación superior. Las tendencias propuestas son las siguientes: el papel de la Educación Superior en la construcción del conocimiento; la calidad, la pertinencia y la relevancia; la inclusión y la equidad; la diversificación, la diferenciación y la segmentación; la integración, la cooperación internacional, redes y asociaciones.

El análisis de las tendencias, se articulará a los problemas, retos y variables que caracterizan a la educación superior y que se enmarcan en las siguientes temáticas: Bajas tasas de matrícula; baja inversión en Ciencia y Tecnología; transnacionalización, comercio educativo y captación de recursos humanos a través de programas académicos desiguales y fuga de talentos. 
Estudios complementarios y de apoyo deben de facilitar el análisis de las tendencias propuestas; es el caso del estudio comparativo de las legislaciones y de las reformas universitarias ocurridas en los últimos años; el estudio de los sistemas de evaluación, acreditación y certificación de la calidad y, finalmente, estudios relacionados con el gobierno, la gobernanza y la gobernabilidad en las instituciones.

Todo lo anterior constituye una apretada síntesis del trabajo que con la colaboración de todos los universitarios de la región hemos de emprender para analizar la real situación de nuestras Universidades y cómo estas realidades se insertaran en la educación superior de Colombia, que con toda responsabilidad hay que señalar NO es ajena a lo aquí resumido. Con la determinación que sea la ciudad de Cartagena, sede en el año 2008, se presentará una excelente oportunidad para liderar los preparativos de la reunión mundial.
La Universidad colombiana, se debe constituir en actor principal de la educación superior, ya que es ella, la organización llamada a liderar la reconstrucción nacional a partir de la defensa de los valores que orienten las acciones políticas y sociales que, con urgencia, demanda nuestro país. La formación en los diferentes niveles que ofrece la educación superior, no debe presumir que la calidad, sólo se debe referir a los aspectos académicos, sino que es imprescindible analizar las condiciones en las cuales se realiza el trabajo universitario. Las relaciones Universidad-Sociedad, desde sus realidades nacionales e internacionales, debe potenciar su acción transformadora, para concretar sus actividades centradas en temas relacionados con la paz, la promoción de la justicia y de los derechos humanos y la interculturalidad. Una reunión mundial de Educación Superior debe de movilizar a todos sus actores, con el único objetivo de atender los desafíos para transformar y renovar la sociedad contemporánea. 